\title{
TECHNOLOGY IN SUPPORT OF LANGUAGES OF THE PACIFIC: NEO-COLONIAL OR POST-COLONIAL?
}

\author{
Nick Thieberger \\ University of Melbourne, contact: thien@unimelb.edu.au
}

\begin{abstract}
The Pacific and Regional Archive for Digital Sources in Endangered Cultures (PARADISEC) has been digitising recordings of traditional cultural expression, oral tradition, and music (TCE) for 17 years. A major motivation for this work is the return of these recordings to where they were made. On the one hand there is social justice in preserving records of languages that are under-represented in the internet and cultural institutions, and making them accessible in what can be characterised as a postcolonial restitution of these records. On the other hand, if it is first world academics doing this work, it risks being yet another colonial appropriation of Indigenous knowledge. In this paper I explore some of these issues to help set directions both for our own work, and for future similar projects.
\end{abstract}

"From ancient times to the present, disquieting use has been made of archival records to establish, document, and perpetuate the influence of power elites." (Jimerson, 2007: 254).

A quarter of the world's languages are found in the Pacific. In communities sustained over many hundreds of years by local economies, the globalised world impinges through urbanisation and encroaching metropolitan languages, particularly in media, accelerating language change and language shift. Technology, in the form of computers, digital files, and ways of working with them, is a first world product, access to it is costly, and the interface to it is never in a local language but always in a major metropolitan language. Training and experience in using technology is not easily obtained, leading to a divide between those who are able to use it and those who are consumers of it, typically via expensive internet connections. How can a new kind of archival enterprise "establish, document, and perpetuate" the languages and their speakers, in order to counter what Jimerson calls the influence of power elites.

\section{Keywords}

Technology support, Metropolitan language, Pacific region, Traditional cultural expression

Linguistic research has been actively pursued in the Pacific since first colonisation, by missionaries, and later by academic researchers. This, and the work of others, including musicologists and anthropologists, created primary records of traditional cultural expression (TCE) which can be of great interest to the source communities for whom there are few records available, especially in public spaces such as the internet, libraries, and so on. Errington (2001) provides a critique of what he considers to be the colonial nature of linguistics, focussing on the project of reifying language varieties as standard forms, developing writing systems for them, and using languages in Christian proselytising. It is not surprising that linguistics, just as any other part of the imperialist project, can be critiqued as colonial in this way. However, I am more concerned in this discussion to consider the practice of academics in the past, who, in general did not provide a means for curating recordings and making them accessible for the source communities, and to contrast that with the possibility of restitution of expropriated primary records - recordings, photographs, and so on.

Here, I want to present a practical notion of responsibility with regard to recorded TCE, one that I suggest is post-colonial in simply providing access to recordings for people whose languages and cultures were earlier treated as objects of study. These recordings are otherwise at risk of being lost, but potentially have value as some of the few records available in a local language. The responsibility is that of academics to ensure that records made with indigenous 
people are available to those people as soon as possible after they are recorded. A further responsibility for the research community is locating existing analog recordings made in the past and making them available for use by speakers today. In this way, and as Jimerson (2007: 256) notes, archives contribute to the public interest "by documenting underrepresented social groups and fostering ethnic and community identities." Similarly, Smith observes that

\footnotetext{
"imperialism and colonialism brought complete disorder to colonized peoples, disconnecting them from their histories, their landscapes, their languages, their social relations and their own ways of thinking, feeling and interacting with the world. It was a process of systematic fragmentation which can still be seen in the disciplinary carve-up of the indigenous world: bones, mummies and skulls to the museums, art work to private collectors, languages to linguistics, 'customs' to anthropologists, beliefs and behaviours to psychologists. To discover how fragmented this process was one needs only to stand in a museum, a library, a bookshop, and ask where indigenous peoples are located." (Smith 1999: 28)
}

I suggest that the process of making records of TCE available addresses some of Smith's concerns, but I begin by briefly sketching the colonial nature of academic research that is based in fieldwork among indigenous people. This is necessarily brief as I take it to be self-evident that the academic research enterprise, especially in the early to mid-late twentieth century, regarded speakers of indigenous languages as sources of information, and rarely as participants in the research. Recordings were typically not made available to those people, and, as will be clear from the effort required to find and digitise these recordings, provision was not made for the recordings to be suitably housed so that they could be accessed into the future.

Linguistics has, as one of its objects, the study of each of the world's languages, typically requiring fieldwork in which a linguist goes to live in a village to learn the language and to write an analysis of it, in the form of a grammatical description. This is critically important in linguistics and can be likened to taxonomic work in biology. This basic research strengthens theoretical claims by expanding the number and type of languages included in the typological analysis.

In the past there has been little awareness of the extractive nature of this work, and a corresponding lack of attention paid to creation of materials that could be of use to the local community. We can see this reflected in how published guides to fieldwork, produced to train new linguists, characterise or else ignore linguistic data management - the necessary prerequisite for preserving the records made during fieldwork. Most such guides offer sample wordlists and sample sentences for elicitation (e.g. Bouquiaux and Thomas, 1992; Samarin, 1967). Some go further and briefly discuss issues around preparation for fieldwork (e.g. Abbi, 2001; Vaux and Cooper, 1999). The anthropologists Fischer (2009) make no mention of 'data', 'recordings', or 'archiving'. While Bouquiaux and Thomas (1992) and Newman and Ratliff (2001) include advice about recording techniques, neither mentions 'data', or 'archiving' of the recordings. Similarly, none of these cases considers the possibility of speakers wanting recorded language material for later reuse. The linguistic discipline's focus on elicited sentences and 'pure' or 'traditional' language (as seen in these fieldguides) mean that the records do not reflect everyday spoken interactions and so are of limited use in language revitalisation efforts (Amery, 2009).

By the turn of the $21^{\text {st }}$ century, we see fieldguides that are starting to pay attention to linguistic data management. Crowley (2007), Chelliah and de Reuse (2010), and Bowern (2008) discuss archiving and data management, and Thieberger and Berez (2012) is a chapter devoted to methodology for creating and archiving linguistic records in a fieldwork volume focused on interdisciplinarity in fieldwork (Thieberger, 2012). The most up-to-date guide is Meakins, Green and Turpin (2018: 73-95), which provides detailed information about data management and archiving. More information on the changes in language recording practice over the past 
generation can be found in Thieberger (2016), but it will simplify our discussion to characterise the new approach to fieldwork and resulting material as language documentation (Himmelmann, 1998). Lest it appear that these advances in methodology have succeeded in changing all fieldwork practice, there are still recalcitrants for whom considerations of data sharing and archiving are a distraction from what they consider to be the real work of academic research. For example, Aikhenvald (2007: 7) claims that technology is itself neo-colonial,

"[t]here is no doubt that putting conversations, texts and other information on the world wide web, and producing videos and web-based archives, is close to the heart of many of our computerloving linguistic colleagues. ... Putting web-based data together may be easier and quicker than painstakingly writing a grammar, and producing a competent dictionary. But web-based archives need constant updating, and book pages do not. And if a language is spoken in a remote community, say, in Amazonia, Africa or New Guinea, what use is a website to them?"

Here we see technology represented as colonial and inaccessible to remote communities, a seemingly reasonable critique, after all, electricity is not common in many remote areas, and, if internet access is available, then bandwidth is expensive. However, the basic premise of this argument is that, in response to the lack of access in some geographical areas, we, as academic researchers, should not create digital files and archive them, seemingly a non sequitur, until one sees that Aikhenvald confuses archives, which are long-term repositories, with websites, which we have come to learn, often to our cost, are a transient presentation of information. This kind of argument ignores our responsibility to create re-usable primary records and does not understand that creating proper records with the best methods now will also allow it to be returned to the community in various formats that can be accessed now. It fails to acknowledge that access to the internet is ever-expanding, with the result that, at some point in the not too distant future, people in even the most remote locations will be searching for their language records online.

Another reaction against appropriate language data management methodologies is Dobrin, Austin and Nathan (2007) who reject the need for standards in metadata and file formats in linguistic research. These authors say that, "quantifiable properties such as recording hours, data volume, and file parameters, and technical desiderata like 'archival quality' and 'portability' have become commonplace reference points in assessing the aims and outcomes of language documentation [..] technical parameters such as these are now foregrounded to the point that they are eclipsing discussions of documentation methods." (Dobrin, Austin and Nathan, 2007: 62) There is no basis for this assertion and it must be pointed out that, without the use of community-agreed standards for file formats, file management and archiving are made more difficult. Simple guidelines provided by archives to linguists allow the creation of 'archive-ready' material that can be accessed by the linguist and the speakers of the language in future.

It is of some small comfort to note that, despite this kind of backlash, the field of language and music archiving is probably more advanced than is the case for other disciplines. There is an international community of digital archives in the Digital Endangered Languages and Musics Archives Network $\left(D_{E L A M A N}{ }^{1}\right.$ ), and the Open Language Archives Community ${ }^{2}$ (OLAC) has, since 2000, provided a set of standard metadata terms for archives to use in describing items in collections. Because of this international standard, OLAC can harvest metadata from each of the member archives, building an aggregated directory of all their contents that is refreshed

\footnotetext{
1 http://delaman.org, last accessed 28 May, 2020.

2 http://www.language-archives.org/, last accessed 28 May, 2020.
} 
daily. This then creates a webpage for each language in the world, listing what is available in all of the participating archives for that language.

The virtuous post-colonial environment I have been portraying so far is only partially altruistic. In reality, the nature of research data management has changed in the past decade so that many of the issues that characterise language documentation also have currency across all disciplines, and are being led by the sciences, for whom primary data has always been regarded as integral to research (e.g. Tenopir et al, 2011). So, while it is still controversial among some linguists (among them those cited above) that we work with data at all, and that we need to pay attention to data management, it is much clearer in science disciplines that data must be citable and experiments must be replicable. Digital data has also facilitated the rapid transfer of files, stored in multiple locations, but its evanescence (Thieberger, 2018) prompts us to concentrate on backup and data management techniques, including building repositories to curate files in the longterm.

There is an increasingly large cohort of newly trained linguists and musicologists who take seriously the need to produce re-useable records in the course of their research, and to archive them as soon as possible, in order to create citable data they can use in their research ${ }^{3}$. There is a prize ${ }^{4}$ offered for the best collection of primary data created by an early career researcher. There are policy suggestions for acknowledging properly curated primary data collections as valid research outputs (Thieberger et al, 2016), and discussions of citation practices for primary data (Berez-Kroeker et al, 2019). Taken together, this practice acknowledges the professional responsibility of researchers to ensure their work is accessible to the people they work with. Even this small effort should be seen as post-colonial practice, and incorporated into training for current and future fieldworkers.

\section{REPATRIATION}

The practice of repatriating Indigenous human remains (Fforde and Ormond-Parker, 2001) is well-known and continually developing ${ }^{5}$. Equally well-known are the egregious examples of collecting agencies that will not return material, clinging instead to the vestiges of their colonial past. A related activity is repatriation of cultural materials, including audio, video, or manuscript records. Such collections could be the result of fieldwork by an outside researcher, or be made by speakers of their own communities. In Vanuatu the fieldworkers in the Vanuatu Kaljoral Senta (VKS) made many recordings that are today held in the museum building in Port Vila. One of the foundational fieldworkers, James Gwero, did this work, because "people were saying the white men had come and stolen their voices" (Kapere, 2011:137) and he was determined that his recordings would instead be held by the VKS. However, there is a risk in analog tapes being held in just one location as illustrated by the fire at the National Museum of Brazil in September 2018 that destroyed many unique paper and recorded materials in languages of Brazil.

In the past, analog recordings relied on there being local machines that could play reel to reel tapes or cassettes. Even with the occasional return of an analog tape to its source community, analog media deteriorated with each playback, and required dry and dust-free conditions to be stored in, something that was not always possible in dry, dusty, or humid environments. Analog tapes, by their nature, are not easily copied, and getting analog records back to the places they

\footnotetext{
3 These notions crystallised in the wider research community into the FAIR principles ${ }^{3}$, published in 2016, which set out the goals of Findable, Accessible, Interoperable, and Re-usable research data. Each of these principles is reflected in the practice developed by PARADISEC, as discussed here and in Barwick and Thieberger (2016).

4 http://www.delaman.org/delaman-award/, last accessed 28 May, 2020.

5 Project 'Return, Reconcile, Renew', https://returnreconcilerenew.info, last accessed 28 May, 2020.
} 
came from has been an arduous task in the past that was usually not undertaken, in no small part due to a colonial approach in which information is extracted for the benefit of the researcher alone.

Digitisation provides a means for making records available and for storing them in the longterm, in several locations as, unlike their analog sources which deteriorate with each generation of copying, each digital copy is identical. Digital archiving and delivery of records changes access and promises a shift towards a post-colonial practice, while at the same time highlighting the technological gap between the local community and the archive. These are issues we are addressing in our work at the Pacific and Regional Archive for Digital Sources in Endangered Cultures (PARADISEC) ${ }^{6}$, a project running since 2003 that seeks analog ethnographic recordings, digitises them, and makes them available online (subject to conditions established by depositors). We have so far put 12,400 hours of recordings online, each with licences for use, representing 1,235 languages. As with any collection hosted in a first-world country we are aware that we perpetuate appropriation of cultural material, however, it would be equally problematic to ignore the importance of preserving cultural records and of making them available to the people represented in them. Further, as should be clear from the discussion here, digital records can overcome the inherent problem of the analog in that digital records can be made available in many places and over time in a way that analog records could not.

In addition, we are actively working with a range of cultural agencies in our region to make the recordings known to them, to provide copies of recordings, and to support their own efforts to digitise their collections of analog records. For example, we have applied for and received grants to digitise hundreds of analog tapes from the Solomon Islands National Museum ${ }^{7}$, The University of French Polynesia ${ }^{8}$, and the Divine Word University in Madang (PNG $)^{9}$. PARADISEC have been working with the VKS and have digitised more than 200 of their tapes, including many open reels that were mouldy and for which there was no playback machine in Port Vila ${ }^{10}$.

Recordings in some of the many languages of the Pacific can be found in collections all over the world, along with the artefacts and other cultural items taken in the colonial enterprise. These collections may be housed in institutional libraries or similar repositories, or, more often, they are found in the offices of researchers, in their houses once they retire, or in their deceased estates once they die, in general, they are not treated with the respect they deserve.

We set up an online questionnaire called 'Lost and Found' ${ }^{11}$ and periodically seek information about 'orphaned' collections of oral tradition on analog tape that need to be preserved. These include tapes in deceased estates, or tapes in offices and homes of older or retired researchers. As a result, we have digitised many collections of field recordings that would otherwise have been lost, as there are too few digital archives that focus on this kind of material. One major collection we have digitised was made by the Catholic priest Fr John Z'graggen in the region around Madang in PNG from the 1960s onwards. It was held in the Basel Museum in Switzerland (172 tapes), and some copies and originals were also stored in Madang at the Divine Word University (180 tapes). After long negotiations with the Basel Museum they agreed to have the entire collection digitised and, rather than shipping tapes to Australia, we

\footnotetext{
6 http://paradisec.org.au, last accessed 28 May, 2020.

7 https://catalog.paradisec.org.au/collections/SINM, last accessed 28 May, 2020.

8 https://catalog.paradisec.org.au/collections/EC1, last accessed 28 May, 2020.

9 https://catalog.paradisec.org.au/collections/DWU, last accessed 28 May, 2020.

$10 \mathrm{https} / / /$ catalog.paradisec.org.au/collections/VKS2, last accessed 28 May, 2020.

11 https://www.delaman.org/project-lost-found/, last accessed 28 May, 2020.
} 
arranged with our colleagues at the Max Planck Institute in Nijmegen to have them digitised there and then made available for us to archive ${ }^{12}$. We applied for and received funds from the Endangered Languages Documentation Programme's Legacy Materials Grants and worked with the DWU to digitise those tapes from Madang ${ }^{13}$. With a similar grant, we digitised 260 tapes in To'aba'ita (Solomon Islands) that were in the retired researcher's house ${ }^{14}$ in Christchurch, New Zealand, and then sent copies of the files to the Solomon Islands National Museum.

The list of taped collections at risk keeps growing, despite the work of PARADISEC and similar allied efforts. At the same time, we are facing the imminent demise of audio carriers - analog tapes are not expected to be playable in the very near future, and playback machines are slowly going out of service (National Film and Sound Archive, 2015).

We increase the reach of our catalog ${ }^{15}$ via feeds to external services such as OLAC (mentioned earlier), the Open Archives Initiative, Research Data Australia ${ }^{16}$, and the National Library of Australia's Trove ${ }^{17}$. These feeds are then picked by other services and so make our collection more visible in a number of search tools, like the Virtual Language Observatory ${ }^{18}$. We are also building methods for delivering sub-collections of items on local WIFI transmitters ${ }^{19}$, aimed at regional cultural centres. This has the advantage of avoiding expensive and slow internet connections, and of being available on smartphones which are becoming increasingly common in Pacific island nations. We have written a tool, the 'data-loader' ${ }^{20}$, that runs over a selection of arbitrarily grouped items from the collection, each of which is stored together with a file of its own metadata description. This then generates a static catalog of just the selected files and makes the collection more meaningful for a user than would be a set of files that are divorced from the catalog. The html catalog is designed to work either on a hard disk or on a raspberry pi WIFI transmitter to make the collection available in the most suitable way for local access. We have trialled this at various locations in the Pacific and found it to be an appropriate and relatively simple way to make archival materials available to mobile phone users, avoiding internet costs. As data is stored on a usb device, we can envisage sending collections to local cultural centres over time. All of this helps in restitution of cultural records.

There is a choice to be made between doing nothing about the cultural heritage we and our forebears have recorded, and so allowing it to be lost, or to take some action to ensure it is available to the people most interested in it. As Chambers et al (2002: 214) note:

\footnotetext{
"simple inaction is almost always the worst choice to make. "Doing nothing" is actually a choice too. ... Thoughtful repatriation of ethnographic materials can assist not only in the decolonization of anthropology, but in empowering both communities and the people who comprise them by allowing easier access to a greater range of ethnographic information."
}

\footnotetext{
$12 \mathrm{https} / / /$ catalog.paradisec.org.au/collections/JZ1, last accessed 28 May, 2020.

$13 \mathrm{https} / / /$ catalog.paradisec.org.au/collections/DWU, last accessed 28 May, 2020.

${ }^{14} \mathrm{https}$ ://catalog.paradisec.org.au/collections/IF01, last accessed 28 May, 2020.

15 https://catalog.paradisec.org.au, last accessed 28 May, 2020.

$16 \mathrm{https} / / /$ researchdata.ands.org.au/paradisec-collection/, last accessed 28 May, 2020.

$17 \mathrm{https}: / /$ trove.nla.gov.au/result?q=nuc\%3A\%22NU\%3APAR\%22, last accessed 28 May, 2020.

18 https://vlo.clarin.eu, last accessed 28 May, 2020.

19 https://language-archives.services/about/pi, last accessed 28 May, 2020.

${ }^{20} \mathrm{https} / / /$ language-archives.services/about/data-loader, last accessed 28 May, 2020.
} 


\section{CONCLUSION}

The race to digitise analog recordings is our responsibility, as linguists, musicologists, and anthropologists, both in order to honour the work of our academic forebears, and to complete the more modern research cycle of repatriation of recordings. While the relationship between academics focussed on a research topic and speakers of a language will always be fraught with power imbalance, making recordings and returning them to the community is a necessary and increasingly common form of exchange. To the extent that we are making available the records that we created with speakers of languages we study, this activity can be considered postcolonial restitution. I have shown that a repository like PARADISEC can provide access to recordings and so avoid the grace and favour approach that was often the only way that recordings could be obtained in the past.

\section{REFERENCES}

Abbi, Anvita. 2001. A manual of linguistic fieldwork and structures of Indian languages. München: Lincom Europa.

Aikhenvald, Alexandra Y. 2007. Linguistic fieldwork: setting the scene. Sprachtypologie und Universalienforschung [Language Typology and Universals], 60(1): 3-11.

Amery, Rob. 2009. Phoenix or Relic? Documentation of Languages with Revitalization in Mind. Language Documentation \& Conservation 3(2):138-148.

Barwick, Linda and Nick Thieberger. 2018. Unlocking the archives. Communities in Control: Learning tools and strategies for multilingual endangered language communities. Proceedings of the 2017 XXI FEL conference. Edited by Vera Ferreira and Nick Ostler. Hungerford: FEL, 135-139.

Berez-Kroeker, Andrea L. Lauren Gawne, Barbara F. Kelly, Tyler Heston, Susan Kung, Gary Holton, Peter Pulsifer, David Beaver, Shobhana Chelliah, Stanley Dubinsky, Richard Meier, Nicholas Thieberger, Keren Rice and Anthony Woodbury. 2018. Reproducible research in linguistics: A position statement on data citation and attribution in our field. Linguistics 56(1): 1 - 18.

Chambers, Anne, Keith S. Chambers, David R. Counts, Dorothy A. Counts, Suzanne Falgout, Nancy Guy, Alan Howard, Sjoerd R. Jaarsma, Mary McCutcheon, Bryan P. Oles, Karen M. Peacock, and Amy Ku'uleialoha Stillman. 2002. Returning Ethnographic Materials. Handle with Care: Ownership and Control of Ethnographic Materials. ASAO Monograph Series, no. 20. Edited by S. R. Jaarsma. Pittsburgh: University of Pittsburgh Press, 211-214.

Dobrin, Lise M., Peter K. Austin and David Nathan. 2007. Dying to be counted: the commodification of endangered languages in documentary linguistics. Proceedings of Conference on Language Documentation and Linguistic Theory. Edited by Peter K. Austin, Oliver Bond \& David Nathan. London: SOAS, 59-68.

Bouquiaux, Luc and Jacqueline Thomas, eds. 1992. Studying and describing unwritten languages. Dallas: Summer Institute of Linguistics.

Bowern, Claire. 2008. Linguistic Fieldwork. A Practical Guide. New York: Palgrave Macmillan.

Chelliah, Shobhana L. and Willem J De Reuse. 2010. Handbook of Descriptive Linguistic Fieldwork. Dordrecht: Springer Science \& Business Media.

Crowley, Terry. 2007. Field Linguistics. Oxford: OUP.

Errington, Joseph. 2001. Colonial linguistics. Annual Review of Anthropology 30: 16-39.

Fischer, Michael M. 2009. Fieldwork Is Not What It Used to Be: Learning Anthropology's Method in a Time of Transition. Edited by James D. Faubion and George E. Marcus. Ithaca/ London: Cornell University Press.

Fforde, Cressida and Lyndon Ormond-Parker. 2001. Repatriation Developments in the UK. Indigenous Law Bulletin 5(6): 9-13.

Himmelmann, Nikolaus. 1998. Documentary and Descriptive Linguistics. Linguistics 36(1): 161-196.

Jimserson, Randall C. 2007. Archives for All: Professional Responsibility and Social Justice. The American Archivist 70 (2): 252-281. 
Kapere, Jacob. 2011. Vanuatu National Film Unit. Working Together in Vanuatu: Research Histories, Collaborations, Projects and Reflections. Edited by John Taylor and Nick Thieberger. Canberra: ANU Press, 133-140.

Meakins, Felicity, Jennifer Green and Myfany Turpin. 2018. Understanding Linguistic Fieldwork. London: Routledge.

National Film and Sound Archive (Australia). 2015. DEADLINE 2025 - Collections at Risk Canberra: NFSA.

Newman, Paul, and Martha Ratliff, eds. 2001. Linguistic Fieldwork. Cambridge: Cambridge University Press.

Samarin, William. J. 1967. Field Linguistics: A Guide to Linguistic Field Work. New York: Holt, Reinhart, and Winston.

Smith, Linda Tuhiwai. 1999. Decolonizing Methodologies: Research and Indigenous Peoples. London ; New York : Zed Books ; Dunedin, N.Z. : University of Otago Press.

Tenopir, Carol, Suzie Allard, Kimberly Douglass, Arsev Umur Aydinoglu, Lei Wu, Eleanor Read, Maribeth Manoff and Mike Frame. 2011. Data Sharing by Scientists: Practices and Perceptions. PLoS ONE 6(6): e21101.

Thieberger, Nick, ed. 2012. The Oxford Handbook of Linguistic Fieldwork. Oxford: OUP.

Thieberger, Nick. 2014. Curation of Oral Tradition from Legacy Recordings: An Australian Example. Oral Tradition, 28 (2): 253-260.

Thieberger, Nick. 2016. Documentary Linguistics: Methodological Challenges and Innovatory Responses. Applied Linguistics, 37 (1):88-99.

Thieberger, Nick. 2018. Research methods in recording oral tradition: Choosing between the evanescence of the digital or the senescence of the analog. Research Methods in the Digital Humanities Edited by Lewis Levenberg, Tai Neilson and David Rheams, (eds) Cham: Palgrave Macmillan, 233-241.

Thieberger, Nick and Andrea Berez. 2012. Linguistic Data Management. The Oxford Handbook of Linguistic Fieldwork. Edited by Nick Thieberger. Oxford: OUP, 90-118.

Thieberger, Nick, Amanda Harris and Linda Barwick. 2015. PARADISEC: Its History and Future. Research, Records and Responsibility: Ten Years of the Pacific and Regional Archive for Digital Sources in Endangered Cultures (PARADISEC). Edited by Amanda Harris, Nick Thieberger and Linda Barwick. Sydney: Sydney University Press, 1-16.

Thieberger, Nick, Anna Margetts, Stephen Morey and Simon Musgrave. 2016. Assessing Annotated Corpora as Research Output. Australian Journal of Linguistics. Vol 36 (1), 1-21.

Vaux, Bert, Justin Cooper and Ben Tucker. 2007. Linguistic Field Methods. Eugene: Wipf \& Stock.

\section{Web Pages}

catalog.paradisec.org.au, last accessed 28 May, 2020.

catalog.paradisec.org.au/collections/DWU, last accessed 28 May, 2020.

catalog.paradisec.org.au/collections/EC1, last accessed 28 May, 2020.

catalog.paradisec.org.au/collections/IF01, last accessed 28 May, 2020.

catalog.paradisec.org.au/collections/JZ1, last accessed 28 May, 2020.

catalog.paradisec.org.au/collections/SINM, last accessed 28 May, 2020.

catalog.paradisec.org.au/collections/VKS2, last accessed 28 May, 2020.

delaman.org, last accessed 28 May, 2020.

language-archives.services/about/data-loader, last accessed 28 May, 2020.

language-archives.services/about/pi, last accessed 28 May, 2020.

paradisec.org.au, last accessed 28 May, 2020.

researchdata.ands.org.au/paradisec-collection/, last accessed 28 May, 2020.

trove.nla.gov.au/result?q=nuc\%3A\%22NU\%3APAR\%22, last accessed 28 May, 2020.

vlo.clarin.eu, last accessed 28 May, 2020.

www.delaman.org/delaman-award/, last accessed 28 May, 2020.

www.delaman.org/project-lost-found/, last accessed 28 May, 2020.

www.language-archives.org/, last accessed 28 May, 2020. 


\section{University Library}

\section{- M M N E R VA A gateway to Melbourne's research publications}

Minerva Access is the Institutional Repository of The University of Melbourne

Author/s:

Thieberger, N

Title:

Technology in Support of Languages of The Pacific: Neo-Colonial or Post-Colonial?

Date:

2020

Citation:

Thieberger, N. (2020). Technology in Support of Languages of The Pacific: Neo-Colonial or Post-Colonial?. Asian-European Music Research Journal, 5 (Summer), pp.17-24. https:// doi.org/10.30819/aemr.5-3.

Persistent Link:

http://hdl.handle.net/11343/265938

License:

CC BY-NC-ND 